\title{
Impact of ambient temperature on life loss per death from cardiovascular diseases: a multicenter study in central China
}

\author{
Ling-Shuang $\mathrm{Lv}^{1} \cdot$ Chun-Liang Zhou ${ }^{1}$ (1) $\cdot$ Dong-Hui Jin ${ }^{1} \cdot$ Wen-Jun $\mathrm{Ma}^{2} \cdot$ Tao Liu $^{2} \cdot$ Yi-Jun Xie $^{3} \cdot$ Yi-Qing Xu$^{1}$. \\ Xing-E Zhang ${ }^{1}$
}

Received: 3 August 2021 / Accepted: 30 September 2021 / Published online: 11 October 2021

(c) The Author(s) 2021

\begin{abstract}
Background In the context of global climate change, studies have focused on the ambient temperature and mortality of cardiovascular diseases (CVDs). However, little is known about the effect of ambient temperature on year of life lost (YLL), especially the life loss per death caused by ambient temperature. In this study, we aimed to assess the relationship between ambient temperature and life loss and estimate the impact of ambient temperature on life loss per death.

Methods We collected daily time series of mortality and meteorological data from 70 locations in Hunan province, central China, in periods ranging from Jan. 1, 2013, to Dec. 31, 2017. Crude rates of YLL were calculated per 100,000 people per year (YLL/100,000 population) for each location. A distributed lag nonlinear model and multivariate meta-regression were used to estimate the associations between ambient temperature and YLL rates. Then, the average life loss per death attributable to ambient temperature was calculated.

Results There were 711,484 CVD deaths recorded within the study period. The exposure-response curve between ambient temperature and YLL rates was inverted J or U-shaped. Relative to the minimum YLL rate temperature, the life loss risk of extreme cold temperature lasted for 10 to 12 days, whereas the risk of extreme hot temperature appeared immediately and lasted for 3 days. On average, the life loss per death attributable to non-optimum ambient temperatures was 1.89 (95\% CI, 1.21-2.56) years. Life loss was mainly caused by cold temperature (1.13, 95\% CI, 0.89-1.37), particularly moderate cold (1.00, 95\% CI, 0.78-1.23). For demographic characteristics, the mean life loss per death was relatively higher for males $(2.07,95 \% \mathrm{CI}, 1.44-2.68)$ and younger populations $(3.72,95 \% \mathrm{CI}, 2.06-5.46)$ than for females $(1.88,95 \% \mathrm{CI}, 1.21-2.57)$ and elderly people (1.69, $95 \% \mathrm{CI}, 1.28-2.10)$, respectively.

Conclusions We found that both cold and hot temperatures significantly aggravated premature death from CVDs. Our results indicated that the whole range of effects of ambient temperature on CVDs should be given attention.
\end{abstract}

Keywords Cardiovascular diseases $\cdot$ Ambient temperature $\cdot$ Extreme temperature $\cdot$ Year of life lost $\cdot$ Mortality $\cdot$ Distributed lag nonlinear model

Ling-Shuang Lv and Chun-Liang Zhou contributed equally to this work.

Responsible Editor: Lotfi Aleya

Chun-Liang Zhou

hncdc_zcl@163.com

1 Hunan Provincial Center for Disease Control and Prevention, Changsha 410005, China

2 Guangdong Provincial Institute of Public Health, Guangdong Provincial Center for Disease Control and Prevention, Guangzhou 511430, China

3 Hunan Provincial Climate Center, Changsha 410007, China

\section{Introduction}

Cardiovascular diseases (CVDs) are the leading cause of premature death globally. The Global Burden of Disease Study in 2019 estimated that a total of 9.6 million people died of CVDs, accounting for almost a third of all deaths globally (Collaborators GDaI 2020). The prevalence of CVDs in China has been persistently increasing and remains the major cause of death. In 2017, CVD-related deaths accounted for $45.91 \%$ and $43.56 \%$ of all deaths in rural and urban areas, respectively. Two out of five cases of death were attributed to CVDs (China NCfCD 2020). 
Under the background of climate change, many studies have showed that climate change poses a catastrophic risk to human health and that heat waves result in excess mortality, usually seen in the exacerbation of CVDs (Cai et al. 2021; Yang et al. 2021). Ambient temperature is regarded as an important risk factor for public health (Gasparrini et al. 2015; Son et al. 2019). Recently, the majority of epidemiological studies have demonstrated association between non-optimum ambient temperature exposure and mortality or morbidity of CVDs (Achebak et al. 2019; Dimitrova et al. 2021; Huber et al. 2020; Martínez-Solanas and Basagaña 2019). The findings indicated that high or low temperatures could increase the risks of mortality or morbidity. One systematic review reported that the risk of cardiovascular mortality increased by $5 \%$ for cold exposure and $1.3 \%$ for heat exposure (Moghadamnia et al. 2017). However, those studies have focused on using death counts, relative risk, or attributable fraction as the primary outcome, which may not provide an ideal representation of the total mortality burden attributable to non-optimum temperatures. A major drawback of those health outcomes is that the measures give same the weight to every death occurring at very different ages.

One approach to avoid the shortcoming is to consider years of life lost (YLL) as the health outcome. YLL is a more informative indicator because it combines the number of deaths with age at death, and can give more weight to deaths among younger people (Huang et al. 2012). Compared with relative risk or attributable fraction, YLL can be combined with the number of deaths to calculate the mean life loss per death, which may directly measure the reduction in lifespan (Majdan et al. 2017). Some studies have estimated the exposure-response associations between ambient temperature and YLL (Egondi et al. 2015; Odhiambo Sewe et al. 2018). Recently, one national study reported life loss of CVDs per death attributable to ambient temperature, which used crude YLL rate (YLL per 100,000 population) as a novel measure. The results presented that both high and low temperatures could increase YLL rates of CVDs (Hu et al. 2021). However, the study cannot support more precise impact for specific region, especially for Hunan province, central China. Hunan province have complex and changeable climate, and temperature extremes exhibit a warming trend during the period of 1960-2013 (Chen et al. 2018b). CVDs are the most serious causes of death in the province. So, the impact of ambient temperature on life loss per death from CVDs needs to be explored.

In this study, we conducted a time series analysis including 70 locations in Hunan province, central China. We aimed to explore the impact of ambient temperature on YLL rates, and calculate the mean life loss per death of CVDs attributable to non-optimum ambient temperature.

\section{Methods}

\section{Study location and data collection}

Hunan province is located in central China at $24^{\circ} 38^{\prime}-30^{\circ}$ $08^{\prime} \mathrm{N}, 108^{\circ} 47^{\prime}-114^{\circ} 15^{\prime} \mathrm{E}$, with an area of $211,800 \mathrm{~km}^{2}$. Our study included 70 locations (counties or districts) across Hunan province (Fig. 1). To ensure enough statistical power, only locations with a population size $>200,000$ and/or an annual mortality rate $>4 \%$ o were included ( $\mathrm{Li}$ et al. 2021).

Daily cardiovascular disease mortality data from January 1 , 2013, to December 31, 2017, were obtained. All deaths were classified into groups according to the International Classification of Diseases, 10th revision (ICD-10): total cardiovascular disease (CVD, I00-I99), hypertension (HP, I10-I15), ischemic heart disease (IHD, I20-I25), cerebrovascular disease (CED, I60-I69), hemorrhagic stroke (HS, I60-I62), and ischemic stroke (IS, I63). Information on the sex, date of birth, date of death, and cause of death were included.

Daily average ambient temperature and relative humidity from 698 meteorological monitoring stations across China were extracted from the China Meteorological Data Sharing Service System (http://data.cma.cn/). We used Australian National University Splines (Hutchinson and Xu 2013) to interpolate the daily mean temperature, minimum temperature, maximum temperature, and relative humidity at a $0.01^{\circ}$ $\times 0.01^{\circ}$ spatial resolution across China. We extracted the data of the grids where each selected location was covered and then calculated the average of grids for each location.

\section{YLL rates calculation}

We obtained population size from the sixth national population census conducted in 2010 (China NBoSo 2012). Then, we computed the individual YLL by matching the age and sex of each death to the 100 -year life table. The life table was presented in a previous article (Lv et al. 2020). For each location, daily total YLLs of CVD were calculated by summing all individual YLLs on the same day. After that, we stratified the daily YLLs by sex (male and female), age ( $0-64$ and $\geq 65$ years), and specific cause of death (HP, IHD, CED, HS, and IS). To adjust the effect of population size on total YLL in different locations, we used the YLL rate as a health outcome. Crude rates of YLL were calculated per 100,000 people for each location using the annual population (Luo et al. 2021; Majdan et al. 2017).

\section{Statistical analysis}

We performed all analyses with the R software (Team RC 2020), using the packages dlnm, mvmeta, and ggplot 2 . 

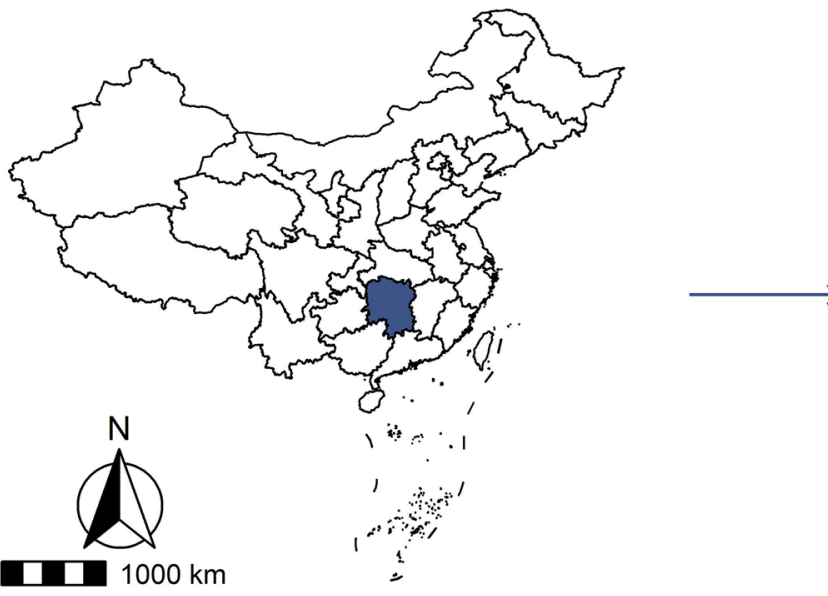

Fig. 1 The geographical distribution of the 70 study sites in Hunan

Two-tailed $P$ values less than 0.05 were considered statistically significant.

\section{Estimation of the association between temperature and YLL rate}

We used a two-stage approach to estimate the association between daily average ambient temperature and the YLL rate of CVDs.

In the first stage, a distributed lag nonlinear model (Gasparrini 2011) linked with a Gaussian distribution function was employed to investigate the location-specific effect, with adjustments for seasonality, long-term trends, day of the week, and daily humidity. Briefly, a natural cubic B-spline of time with 7 degrees of freedom ( $d f s$ ) per year to control for seasonal and long-term trends, and a categorical variable to control the day of the week. We also employed a natural cubic B-spline with $3 d f s$ to adjust the potential confounding effect of relative humidity. A cross-basis function was introduced to model the complex nonlinear and lagged dependencies of the associations between ambient temperature and the YLL rate. Specifically, we modeled the nonlinear associations between ambient temperature and the YLL rate with a quadratic B-spline with three internal knots placed at the 10th, 50th, and 90th percentiles of city-specific daily mean ambient temperature distribution. We modeled the delayed effect with a natural cubic B-spline. We used 21 days as the

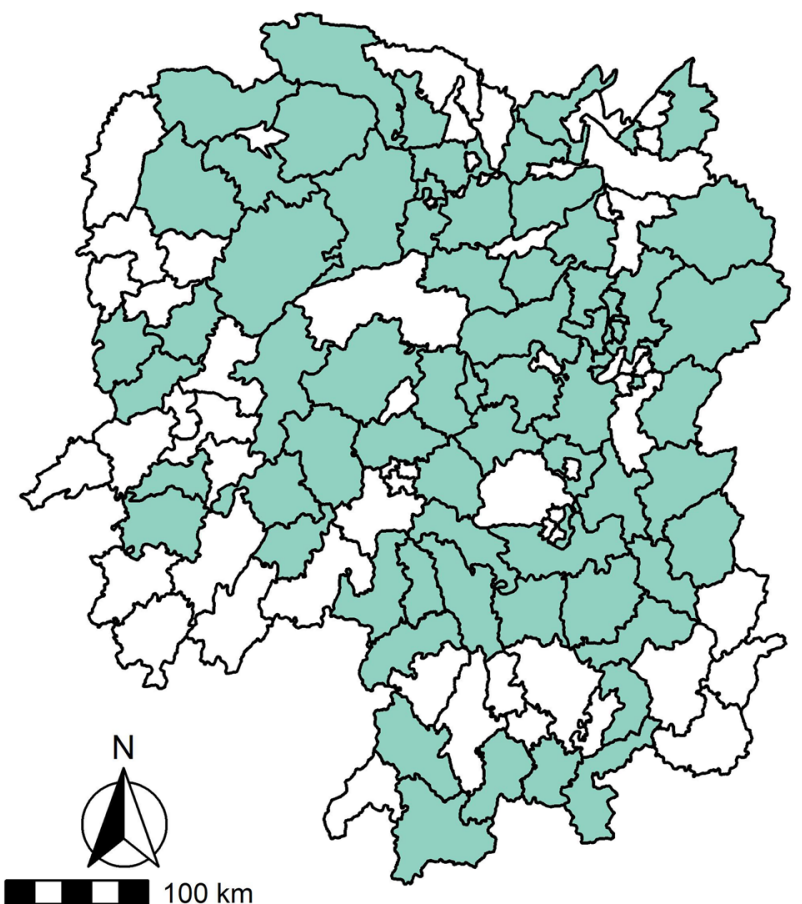

maximum lag period for ambient temperature (Chen et al. 2018a; Gasparrini 2014).

In the second stage, we used a multivariate meta-analytical model (Gasparrini et al. 2012) to pool the best linear unbiased prediction of the location-specific overall cumulative exposure-response associations. The minimum YLL rate temperature (MYT), which corresponds to a minimum YLL rate percentile, was treated as the centring value of the association. We divided daily mean temperatures into four components, extreme cold $(\leq 2.5$ th percentile), moderate cold (the 2.5th percentile to the MYT), moderate heat (MYT to the 97.5th percentile), and extreme heat ( $>97.5$ th percentile). These cut-offs are consistent with previous studies (Chen et al. 2018a; Xu et al. 2019).

\section{Calculation of the average life loss per death attributable to temperatures}

We calculated the daily average YLL per CVD death caused by ambient temperature and its components based on the temperature-YLL rate relationship and population size of each location. The total YLLs attributable to ambient temperature were obtained by accumulating daily attributable YLLs. The average YLLs per death resulting from nonoptimum temperature were calculated by dividing the total attributable YLLs by the number in the respective group or subgroup (Majdan et al. 2017). In order to explore the effect 
modification, $Z$ test was performed to explore the difference between effect estimates for different subgroups. The ratio $z$ $=d / \operatorname{SE}(d) . d$ refers the difference of effect estimates for two categories. $\operatorname{SE}(d)$ refers the square root of the sum of two squares of the separate standard errors (Altman and Bland 2003; Yang et al. 2019).

\section{Sensitivity analysis}

A series of sensitivity analyses were conducted to check the consistency of the results. We employed maximum lag periods of 14,21, and 28 days, changed the $d f s$ of time from 6 to 8 per year, and explored the exposure-response relationship with or without $\mathrm{PM}_{10}$.

\section{Results}

\section{General characteristics}

The distribution of average daily YLL rates of CVDs, related subgroups and weather conditions in the selected cities within the study period are given in Table 1 . In total, 711,484 CVDs deaths were recorded. The mean daily YLL rates for CVD-, CED-, HP-, HS-, IHD-, and IS-related mortality were $10.1,3.7,2.9,1.6,1.2$, and 0.8 per 100,000 population per day, respectively. The average daily YLL rates for males was higher than those for females, and the elderly population (age 65+ years) had much higher YLL rates than the younger population (age 0-64 years). We observed large variations in daily ambient temperature with a mean of $17.7^{\circ} \mathrm{C}$, ranging from -3.5 to 34.5 ${ }^{\circ} \mathrm{C}$. The mean relative humidity was $77.8 \%$. Daily ambient temperature was significantly associated with relative humidity $(r=-0.026, P<0.001)$.

\section{Exposure-response associations of ambient temperatures with YLL rates}

The relationship between temperature and YLL rates of CVD and cause-specific CVDs had an inverted J or U shape, which means that both cold and heat temperatures could increase the YLL rates (Fig. 2). The strongest effects of extreme heat temperature for cause-specific CVDs appeared in CED, followed by HP.

We also explored the delayed effects of extreme ambient temperature on YLL rates. Extreme low temperatures had much larger temperature-attributable YLL rates than extreme high temperatures. The greatest effect of extreme heat (at $31.4{ }^{\circ} \mathrm{C}$, the 97.5 th centile) generally occurred on the first day of exposure and returned to baseline levels within 3 days. However, the risk of extreme cold temperature (at $4.9^{\circ} \mathrm{C}$, the 2.5 th centile) reached a peak 3 days
Table 1 Summary descriptive statistics of study variables in 70 study sites in Hunan, 2013-2017

\begin{tabular}{llllllll}
\hline Type & Mean & SD & Min & $P 25$ & $P 50$ & $P 75$ & Max \\
\hline Total CVD & 10.1 & 7.5 & 0 & 5.0 & 8.8 & 13.7 & 225.5 \\
Sex & & & & & & & \\
$\quad$ Male & 11.4 & 10.2 & 0 & 4.2 & 9.4 & 16.1 & 255.2 \\
$\quad$ Female & 8.8 & 8.5 & 0 & 2.7 & 6.9 & 12.6 & 194.2 \\
Age (years) & & & & & & & \\
0-64 & 4.1 & 5.3 & 0 & 0 & 2.7 & 6.5 & 122.8 \\
$\geq 65$ & 63.6 & 48.9 & 0 & 31.1 & 55.0 & 85.6 & 1760.6 \\
Cause-specific & & & & & & & \\
HP & 2.9 & 3.6 & 0 & 0 & 1.9 & 4.4 & 100.2 \\
IHD & 1.2 & 2.4 & 0 & 0 & 0 & 1.7 & 94.8 \\
CED & 3.7 & 4.2 & 0 & 0 & 2.6 & 5.4 & 113.4 \\
HS & 1.6 & 2.8 & 0 & 0 & 0 & 2.4 & 56.5 \\
IS & 0.8 & 1.7 & 0 & 0 & 0 & 1.1 & 100.2 \\
Meteorological variable & & & & & & & \\
Daily mean temperature $\left({ }^{\circ} \mathrm{C}\right)$ & 17.7 & 8.3 & -3.5 & 10.4 & 18.5 & 24.7 & 34.5 \\
Maximum temperature $\left({ }^{\circ} \mathrm{C}\right)$ & 22.4 & 9.2 & -8.2 & 14.8 & 23.4 & 30.1 & 41.9 \\
Minimum temperature $\left({ }^{\circ} \mathrm{C}\right)$ & 15.0 & 8.1 & -12.7 & 8.1 & 15.6 & 22.1 & 32.5 \\
Relative humidity $(\%)$ & 77.8 & 11.0 & 30.7 & 70.5 & 78.9 & 86.1 & 100 \\
PM & 85.5 & 44.7 & 8.3 & 54.3 & 75.4 & 107.8 & 530.6 \\
\hline
\end{tabular}

$C V D$ total cardiovascular disease, $H P$ hypertension, $I H D$ ischemic heart disease, $C E D$ cerebrovascular disease, $H S$ hemorrhagic stroke, $I S$ ischemic stroke 
Fig. 2 The pooled cumulative exposure-response curves between ambient temperature and YLL rate of CVD and cause-specific CVDs. Solid line, mean YLL rate of mortality. Shaded area, 95\% confidence interval. CVD, total cardiovascular disease; HP, hypertension; IHD, ischemic heart disease; CED, cerebrovascular disease; HS, hemorrhagic stroke; IS, ischemic stroke

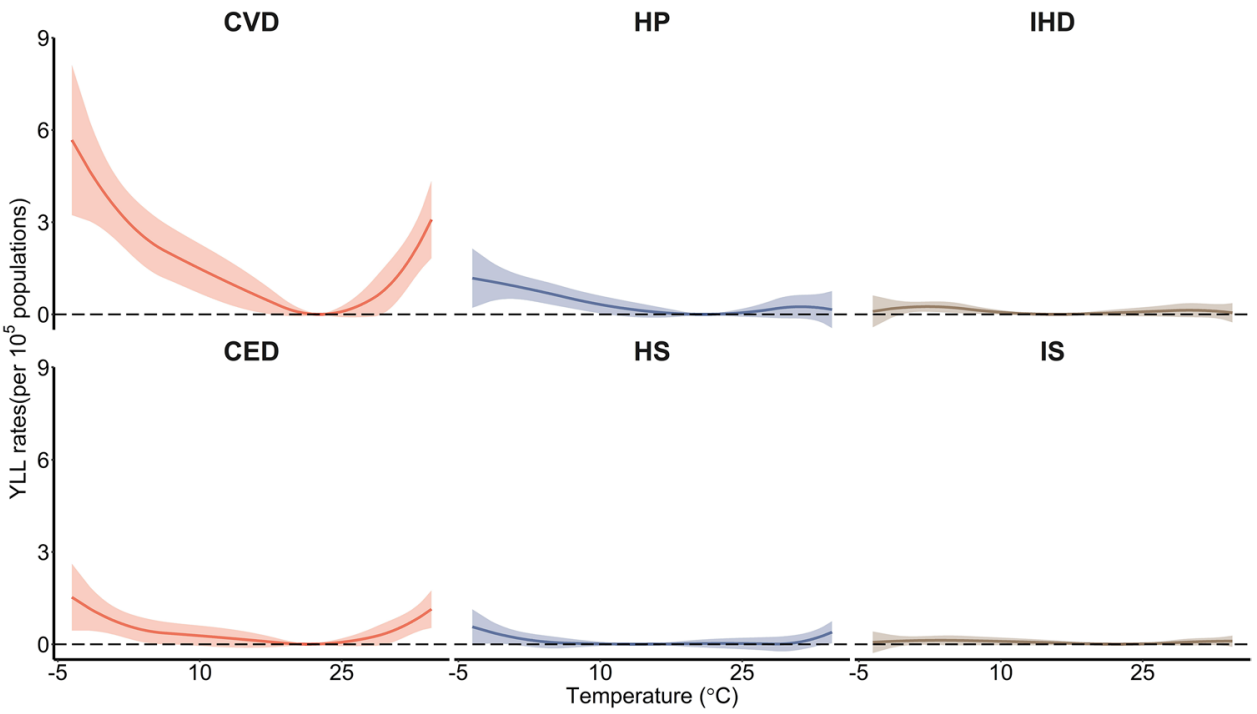

after exposure and declined slightly with a delayed effect even after 10 to 12 days (Fig. 3).

\section{Life loss per death attributable to non-optimum ambient temperature}

An average of 1.89 (95\% CI, 1.21-2.56) life loss per CVD death was associated with non-optimum ambient temperature, out of which 1.13 (95\% CI, 0.89-1.37) years were attributable to cold, particularly moderate cold (1.00 years,

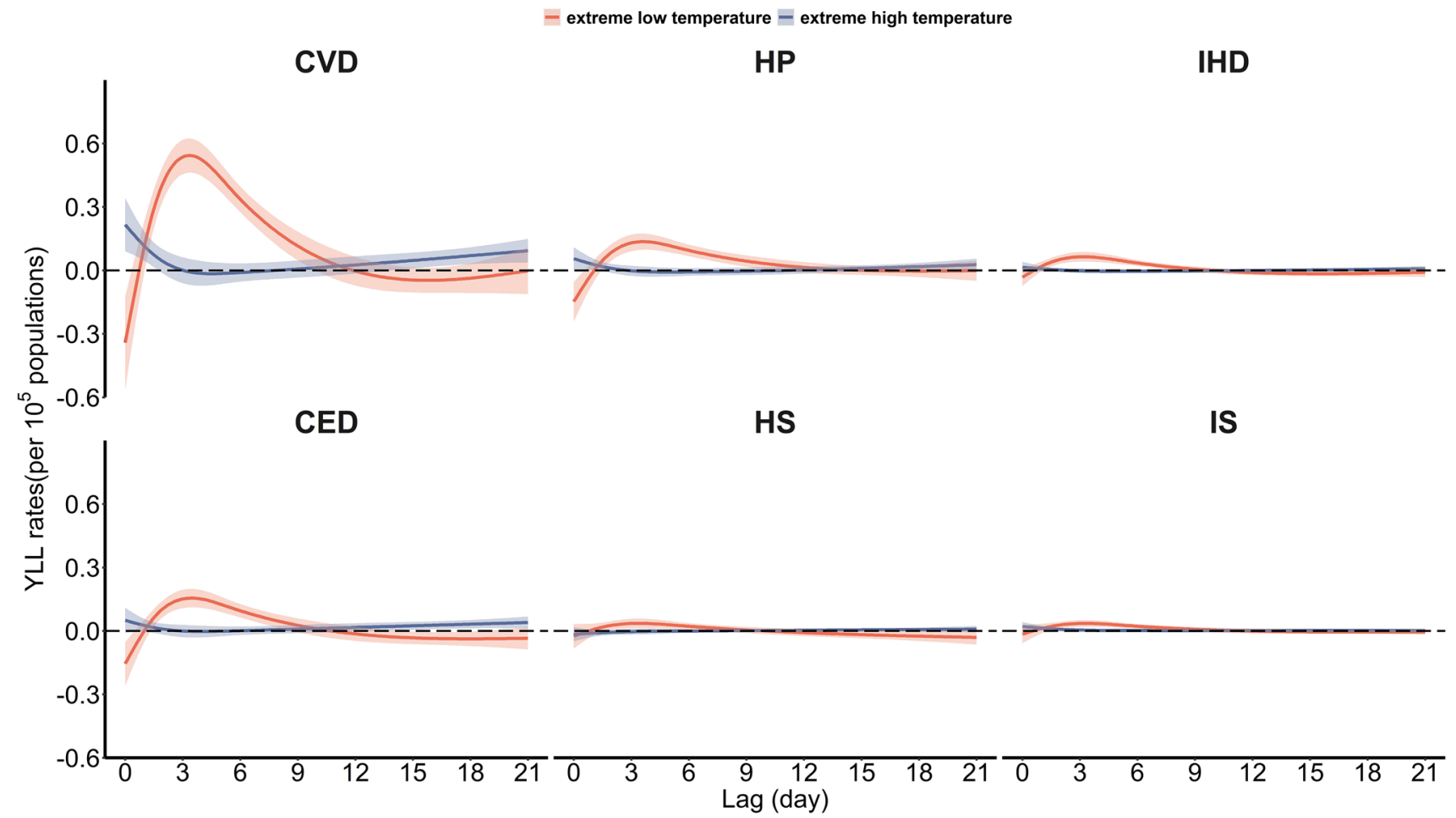

Fig. 3 Overall lag structure in effects of extreme ambient temperature on YLL rate due to CVD and cause-specific CVDs. Solid line, mean YLL rate of mortality. Shaded area, 95\% confidence interval. CVD, total cardiovascular disease; HP, hypertension; IHD, ischemic heart disease; CED, cerebrovascular disease; HS, hemorrhagic stroke; IS, ischemic stroke 
95\% CI, 0.78-1.23). The temperature-attributable life loss per CVD death for males (2.07 years, 95\% CI, 1.44-2.68) and the younger population (3.72 years, 95\% CI, 2.06-5.46) was relatively higher than that for females (1.88 years, $95 \%$ CI, 1.21-2.57) and the elderly population (1.69 years, $95 \%$ CI, 1.28-2.10) (Table 2). We also explore the effect modification of effect estimates for different subgroups. For total ambient temperature, younger population were more vulnerable than elderly population, gender were found to have weak modification effects on the YLL per death (Supplementary Table 1). For cause-specific CVDs, the greatest life loss caused by non-optimum temperature was observed for IS (2.96 years, 95\% CI, 1.50-4.33), followed by HP ( 2.53 years, 95\% CI, 1.79-3.25) (Table 2).

\section{Sensitivity analysis}

When we changed the $d f s$ of long-term trends, the maximum lag day and adjusted the model with or without $\mathrm{PM}_{10}$, the associations between ambient temperature and YLL rates were generally robust (Supplementary figure 1).

\section{Discussion}

In this study, we used the YLL rate to quantify the association between temperature and mortality of CVDs. Nonlinear associations of the temperature-YLL rate relation were found in an inverted $\mathbf{J}$ or $\mathrm{U}$ shape, with an increased YLL rate for both high and low temperatures, which is consistent with previous studies that used relative risk or attributable fractions as health outcomes (Fu et al. 2018; Huber et al. 2020; Ma et al. 2020; Moghadamnia et al. 2018).

Our study explored the mean YLL per death of CVDs caused by temperature, and a mean of 1.89 YLL per death of CVDs was attributable to temperatures in the selected counties within the study period. Our dataset including five different cause-specific CVD deaths enables us to find variations in cause-specific temperature effects. We quantified the average life loss per death of cause-specific CVDs, and found that temperature exposure caused a higher mean life loss for patients with IS than HP, with means of 2.96 and 2.53 , respectively. We also analyzed YLL rates caused by different temperature components. The findings showed that the majority of life loss of CVDs (1.13 years) occurred on cold days below the minimum YLL temperature, and most

Table 2 Life loss per death (years, 95\% CI) attributable to non-optimum ambient temperatures in 70 study sites in Hunan, 2013-2017

\begin{tabular}{|c|c|c|c|c|c|c|c|}
\hline Type & Total & Cold & Heat & Extreme cold & Moderate cold & Moderate heat & Extreme heat \\
\hline Total CVD & $1.89(1.21,2.56)$ & $1.13(0.89,1.37)$ & $\begin{array}{c}0.76(0.13 \\
1.37)\end{array}$ & $\begin{array}{l}0.12(0.11, \\
0.14)\end{array}$ & $1.00(0.78,1.23)$ & $\begin{array}{c}0.67(0.06 \\
1.27)\end{array}$ & $0.09(0.07,0.11)$ \\
\hline \multicolumn{8}{|l|}{ Sex } \\
\hline Male & $2.07(1.44,2.68)$ & $1.45(1.11,1.75)$ & $\begin{array}{c}0.62(0.06 \\
1.16)\end{array}$ & $\begin{array}{l}0.13(0.12 \\
0.15)\end{array}$ & $1.31(0.99,1.61)$ & $\begin{array}{l}0.54(-0.01 \\
1.06)\end{array}$ & $0.08(0.06,0.10)$ \\
\hline Female & $1.88(1.21,2.57)$ & $1.03(0.82,1.27)$ & $\begin{array}{c}0.85(0.19 \\
1.55)\end{array}$ & $\begin{array}{l}0.12(0.10 \\
0.14)\end{array}$ & $0.91(0.70,1.12)$ & $\begin{array}{l}0.75(0.11 \\
1.43)\end{array}$ & $0.10(0.08,0.12)$ \\
\hline \multicolumn{8}{|c|}{$\begin{array}{l}\text { Age of death } \\
\text { (years) }\end{array}$} \\
\hline $0-64$ & $3.72(2.06,5.46)$ & $2.40(1.03,3.66)$ & $\begin{array}{l}1.33(0.20 \\
2.50)\end{array}$ & $\begin{array}{l}0.25(0.22 \\
0.29)\end{array}$ & $2.14(0.81,3.37)$ & $\begin{array}{l}1.21(0.12 \\
2.32)\end{array}$ & $0.11(0.06,0.17)$ \\
\hline$\geq 65$ & $1.69(1.28,2.10)$ & $1.18(0.98,1.36)$ & $\begin{array}{l}0.51(0.14 \\
0.89)\end{array}$ & $\begin{array}{l}0.11(0.10 \\
0.12)\end{array}$ & $1.06(0.88,1.24)$ & $\begin{array}{c}0.43(0.07 \\
0.80)\end{array}$ & $0.08(0.07,0.09)$ \\
\hline \multicolumn{8}{|c|}{ Cause-specific } \\
\hline HP & $2.53(1.79,3.25)$ & $1.89(1.26,2.50)$ & $\begin{array}{l}0.64(0.24, \\
1.03)\end{array}$ & $\begin{array}{l}0.14(0.12 \\
0.17)\end{array}$ & $1.74(1.13,2.35)$ & $\begin{array}{l}0.59(0.19 \\
0.96)\end{array}$ & $0.06(0.04,0.08)$ \\
\hline IHD & $1.44(0.70,2.16)$ & $0.46(0.23,0.70)$ & $\begin{array}{c}0.98(0.32, \\
1.65)\end{array}$ & $\begin{array}{c}0.03(0.02, \\
0.03)\end{array}$ & $0.44(0.21,0.67)$ & $\begin{array}{c}0.94(0.30 \\
1.60)\end{array}$ & $0.03(0.01,0.05)$ \\
\hline CED & $1.36(0.75,1.93)$ & $0.68(0.41,0.95)$ & $\begin{array}{c}0.69(0.12, \\
1.20)\end{array}$ & $\begin{array}{c}0.09(0.07, \\
0.10)\end{array}$ & $0.59(0.33,0.85)$ & $\begin{array}{c}0.59(0.04, \\
1.09)\end{array}$ & $0.10(0.07,0.12)$ \\
\hline HS & $1.25(0.60,1.92)$ & $0.52(0.14,0.92)$ & $\begin{array}{c}0.73(0.17 \\
1.25)\end{array}$ & $\begin{array}{l}0.08(0.05 \\
0.11)\end{array}$ & $0.44(0.09,0.82)$ & $\begin{array}{l}0.65(0.12 \\
1.15)\end{array}$ & $0.08(0.06,0.10)$ \\
\hline IS & $2.96(1.50,4.33)$ & $\begin{array}{c}0.13(-0.03 \\
0.31)\end{array}$ & $\begin{array}{l}2.82(1.38, \\
4.18)\end{array}$ & $\begin{array}{c}0.03(0.02, \\
0.04)\end{array}$ & $\begin{array}{l}0.10(-0.05 \\
0.27)\end{array}$ & $\begin{array}{c}2.73(1.33, \\
4.06)\end{array}$ & $0.09(0.06,0.13)$ \\
\hline
\end{tabular}

$C V D$ total cardiovascular disease, $H P$ hypertension, $I H D$ ischemic heart disease, $C E D$ cerebrovascular disease, $H S$ hemorrhagic stroke, $I S$ ischemic stroke 
were from moderate cold. There could be several reasons for the large fraction of moderate cold effects: (1) prolonged lag effects and the high frequency of moderate cold temperatures; (2) people living in subtropical climate regions, such as Hunan province, central China, may have a higher sensitivity to cold weather and adaptability to hot temperatures (Liu et al. 2020); and (3) exposure to cold temperatures can lead to increased blood pressure, blood viscosity, cardiac load, and serum low-density lipoprotein-cholesterol concentration, all of which contribute to cardiovascular mortality (Gostimirovic et al. 2020; Hong et al. 2012; Lim et al. 2015; Yang et al. 2015). Therefore, appropriate strategies should be established to reduce the mortality burden from the whole range of ambient temperatures.

Recently, climate change has been one of the greatest global health threats (Watts et al. 2017). Extreme temperature events become increasingly frequent. Many studies have provided evidence that extreme temperatures are associated with short-term increases in daily mortality (Adab et al. 2021; Chen et al. 2014; Curtis et al. 2017). Our study adds evidence that extreme temperatures also have an impact on YLL. A mean of 0.12 and 0.09 YLL per CVD patient was attributable to extreme cold and heat temperatures. Our study also showed that extreme heat effects on YLL of CVD occur immediately, while extreme cold effects last longer, which is consistent with the analyses of temperature-mortality studies (Chung et al. 2015; Onozuka and Hagihara 2015). Generally, understanding the lag pattern between temperature exposure and death is important to develop adaptive responses for extreme events.

Moreover, we explored potential effect modification in terms of demographic characteristics, such as sex and age. We found a greater YLL per CVD death in males than in females, indicating that men were more susceptible to nonoptimum ambient temperatures than women. Nevertheless, a systematic review showed that women were more sensitive to the effects of ambient temperature on cardiovascular mortality and morbidity than men (Moghadamnia et al. 2017). A previous study also reported that the heat-attributable fraction of cardiovascular deaths was higher for women and the cold-attributable fraction was larger in men (Achebak et al. 2019). The different physiological and behavioral factors in different regions could explain the discrepancy among the studies. In addition, men are more likely to be exposed to hazardous substances, which results in higher YLL values for males. We also found a higher temperature-related life loss per CVD death in the younger population than in the elderly population during the study period. A low percentage of young people may suffer from CVDs. However, YLL can give more weight to deaths among younger patients; therefore, the mortality burden of each death is heavier (Hu et al. 2021). These findings suggest that when we use YLL per death as a measure, we should pay more attention to men and young people in planning adaptation policies, public health interventions and social services to alleviate the impact of temperature.

Some limitations of our study deserve mention. First, the data we used were limited to Hunan province, central China, and did not include more regions; therefore, the findings may lack generalizability. However, we applied populationrelated YLL rates as health outcomes; therefore, the impacts of ambient temperature on YLL rates in different regions were comparable. Second, similar to many previous studies, some errors cannot be avoided. The study was essentially an ecological study, which could not control individual-level confounders and might have resulted in ecological bias. We used temperature data from weather monitoring stations rather than individual direct measurements, which could lead to exposure measurement bias.

\section{Conclusions}

In summary, we evaluated the corresponding life loss of CVDs attributable to non-optimum temperatures. We found that cold temperature had a stronger impact than heat and showed that moderate cold temperature represented most of the life loss. Our study highlights that public health interventions for climate change are necessary.

Abbreviations CVD: Cardiovascular disease; YLL: Year of life lost; MYT: Minimum YLL rates temperature; HP: Hypertension; IHD: Ischemic heart disease; CED: Cerebrovascular disease; HS: Hemorrhagic stroke; IS: Ischemic stroke; df: Degree of freedom

Supplementary Information The online version contains supplementary material available at https://doi.org/10.1007/s11356-021-16888-7.

Acknowledgements We thank all the study participants.

Author contributions Ling-Shuang Lv: Conceptualization, data curation, methodology, software, writing-original draft, writing-review and editing, and formal analysis. Chun-Liang Zhou: Conceptualization, methodology, project administration, writing-review and editing and formal analysis, and funding acquisition. Dong-Hui Jin: Conceptualization, data curation, methodology. Wen-Jun Ma: Conceptualization, methodology, and visualization. Tao Liu: Software and visualization. Yi-jun Xie: Data curation and methodology. Yi-Qing Xu: Writingreview and editing and formal analysis. Xing-E Zhang: Validation and supervision.

Funding This work was supported by Natural Science Foundation of Hunan Province (2020JJ4388).

Data Availability The meteorological data can be obtained from the China Meteorological Data Sharing Service System (http://data.cma. $\mathrm{cn} /$ ). The mortality data are not publicly available due to the information that could compromise the personal privacy, but the data that support the findings of this study are available from the corresponding author(hncdc_zcl@163.com) upon reasonable request. 


\section{Declarations}

Ethics approval and consent to participate This study was approved by the Ethics Committee of Hunan Provincial Center for Disease Control and Prevention (No. IRB2020018).

\section{Consent for publication Not applicable.}

Competing interests The authors declare that they have no competing interests.

Open Access This article is licensed under a Creative Commons Attribution 4.0 International License, which permits use, sharing, adaptation, distribution and reproduction in any medium or format, as long as you give appropriate credit to the original author(s) and the source, provide a link to the Creative Commons licence, and indicate if changes were made. The images or other third party material in this article are included in the article's Creative Commons licence, unless indicated otherwise in a credit line to the material. If material is not included in the article's Creative Commons licence and your intended use is not permitted by statutory regulation or exceeds the permitted use, you will need to obtain permission directly from the copyright holder. To view a copy of this licence, visit http://creativecommons.org/licenses/by/4.0/.

\section{References}

Achebak H, Devolder D, Ballester J (2019) Trends in temperaturerelated age-specific and sex-specific mortality from cardiovascular diseases in Spain: a national time-series analysis. The Lancet Planetary health 3:e297-e306. https://doi.org/10.1016/ S2542-5196(19)30090-7

Adab C, Via C, Xbab C, Ora C, Cma C, Jba C, Ctab CJEI (2021) Association between ambient temperature and heat waves with mortality in South Asia: systematic review and meta-analysis. Environ Int 146:106170. https://doi.org/10.1016/j.envint.2020. 106170

Altman DG, Bland JM (2003) Interaction revisited: the difference between two estimates. BMJ 326:219. https://doi.org/10.1136/ bmj.326.7382.219

Cai W, Zhang C, Suen HP, Ai S, Bai Y, Bao J, Chen B, Cheng L, Cui X, Dai H et al (2021) The 2020 China report of the Lancet Countdown on health and climate change. Lancet Public Health 6:e64-e81. https://doi.org/10.1016/S2468-2667(20)30256-5

Chen R, Li T, Cai J, Yan M, Zhao Z, Kan H (2014) Extreme temperatures and out-of-hospital coronary deaths in six large Chinese cities. J Epidemiol Community Health 68:1119-1124. https:// doi.org/10.1136/jech-2014-204012

Chen R, Yin P, Wang L, Liu C, Niu Y, Wang W, Jiang Y, Liu Y, Liu J, Qi J et al (2018a) Association between ambient temperature and mortality risk and burden: time series study in 272 main Chinese cities. BMJ 363:k4306. https://doi.org/10.1136/bmj. $\mathrm{k} 4306$

Chen A, He X, Guan H, Cai Y (2018b) Trends and periodicity of daily temperature and precipitation extremes during 1960-2013 in Hunan province, central south China. Theoretical and Applied Climatology 132:71-88. https://doi.org/10.1007/s00704-017-2069-x

China NBoSo. 2012. 2010 sixth national population census data. Available: http://www.stats.gov.cn/tjsj/pcsj/rkpc/6rp/indexch.htm

China NCfCD. 2020. Annual report on cardiovascular health and diseases in China (2019). Available: https://www.nccd.org.cn/ Information/Index/1089

Chung Y, Lim YH, Honda Y, Guo YL, Hashizume M, Bell ML, Chen BY, Kim H (2015) Mortality related to extreme temperature for
15 cities in Northeast Asia. Epidemiology 26:255-262. https:// doi.org/10.1097/EDE.0000000000000229

Collaborators GDaI (2020) Global burden of 369 diseases and injuries in 204 countries and territories, 1990-2019: a systematic analysis for the global burden of disease study 2019. Lancet 396:12041222. https://doi.org/10.1016/S0140-6736(20)30925-9

Curtis S, Fair A, Wistow J, Val DV, Oven K (2017) Impact of extreme weather events and climate change for health and social care systems. Environ Health 16:128. https://doi.org/10.1186/ s12940-017-0324-3

Dimitrova A, Ingole V, Basagana X, Ranzani O, Mila C, Ballester J, Tonne C (2021) Association between ambient temperature and heat waves with mortality in South Asia: systematic review and meta-analysis. Environ Int 146:106170. https://doi.org/10. 1016/j.envint.2020.106170

Egondi T, Kyobutungi C, Rocklov J (2015) Temperature variation and heat wave and cold spell impacts on years of life lost among the urban poor population of Nairobi, Kenya. Int J Environ Res Public Health 12:2735-2748. https://doi.org/10.3390/ijerph120302735

Fu SH, Gasparrini A, Rodriguez PS, Jha P (2018) Mortality attributable to hot and cold ambient temperatures in India: a nationally representative case-crossover study. PLoS Med 15:e1002619. https://doi.org/10.1371/journal.pmed.1002619

Gasparrini A (2011) Distributed lag linear and non-linear models in R: the package dlnm. Journal of statistical software 43:1-20. https://doi.org/10.18637/jss.v043.i08

Gasparrini A (2014) Modeling exposure-lag-response associations with distributed lag non-linear models. Statistics in medicine 33:881-899. https://doi.org/10.1002/sim.5963

Gasparrini A, Armstrong B, Kenward MG (2012) Multivariate metaanalysis for non-linear and other multi-parameter associations. Statistics in medicine 31:3821-3839. https://doi.org/10.1002/sim. 5471

Gasparrini A, Guo Y, Hashizume M, Lavigne E, Zanobetti A, Schwartz J, Tobias A, Tong S, Rocklov J, Forsberg B et al (2015) Mortality risk attributable to high and low ambient temperature: a multicountry observational study. Lancet 386:369-375. https://doi.org/ 10.1016/S0140-6736(14)62114-0

Gostimirovic M, Novakovic R, Rajkovic J, Djokic V, Terzic D, Putnik S, Gojkovic-Bukarica L (2020) The influence of climate change on human cardiovascular function. Arch Environ Occup Health 75:406-414. https://doi.org/10.1080/19338244.2020.1742079

Hong YC, Kim H, Oh SY, Lim YH, Kim SY, Yoon HJ, Park M (2012) Association of cold ambient temperature and cardiovascular markers. Sci Total Environ 435-436:74-79. https://doi.org/10.1016/j. scitotenv.2012.02.070

Hu J, Hou Z, Xu Y, Zhou M, Zhou C, Xiao Y, Yu M, Huang B, Xu X, Lin $L$ et al (2021) Life loss of cardiovascular diseases per death attributable to ambient temperature: a national time series analysis based on 364 locations in China. Sci Total Environ 756:142614. https://doi.org/10.1016/j.scitotenv.2020.142614

Huang C, Barnett AG, Wang X, Tong S (2012) The impact of temperature on years of life lost in Brisbane, Australia. Nature Climate Change 2:265-270. https://doi.org/10.1038/nclimate1369

Huber V, Krummenauer L, Peña-Ortiz C, Lange S, Gasparrini A, Vicedo-Cabrera AM, Garcia-Herrera R, Frieler K (2020) Temperature-related excess mortality in german cities at $2{ }^{\circ} \mathrm{C}$ and higher degrees of global warming. Environ Res 186:109447. https://doi. org/10.1016/j.envres.2020.109447

Hutchinson MF, Xu T. 2013. Anusplin version 4.4 user guide. Available: https://fennerschool.anu.edu.au/files/anusplin44.pdf

Li X, Zhou M, Yu M, Xu Y, Li J, Xiao Y, Huang B, Hu J, Liu T, Guan W et al (2021) Life loss per death of respiratory disease attributable to non-optimal temperature: results from a national study in 364 Chinese locations. Environmental Research Letters 16:035001. https://doi.org/10.1088/1748-9326/abe06c 
Lim YH, Park MS, Kim Y, Kim H, Hong YC (2015) Effects of cold and hot temperature on dehydration: a mechanism of cardiovascular burden. Int J Biometeorol 59:1035-1043. https://doi.org/10.1007/ s00484-014-0917-2

Liu J, Hansen A, Varghese B, Liu Z, Tong M, Qiu H, Tian L, Lau KK-L, Ng E, Ren C et al (2020) Cause-specific mortality attributable to cold and hot ambient temperatures in Hong Kong: a time-series study, 2006-2016. Sustainable Cities and Society 57. https://doi.org/10.1016/j.scs.2020.102131

Luo Z, Lv H, Chen Y, Xu X, Liu K, Li X, Deng Y, Zhou Y (2021) Years of life lost due to premature death and their trends in people with selected neurological disorders in Shanghai, China, 19952018: a population-based study. Front Neurol 12:625042. https:// doi.org/10.3389/fneur.2021.625042

Lv LS, Jin DH, Ma WJ, Liu T, Xu YQ, Zhang XE, Zhou CL (2020) The impact of non-optimum ambient temperature on years of life lost: a multi-county observational study in Hunan, China. Int J Environ Res Public Health 17:2699. https://doi.org/10.3390/ijerp h17082699

Ma Y, Zhou L, Chen K (2020) Burden of cause-specific mortality attributable to heat and cold: a multicity time-series study in Jiangsu Province, China. Environ Int 144:105994. https://doi.org/ 10.1016/j.envint.2020.105994

Majdan M, Plancikova D, Maas A, Polinder S, Feigin V, Theadom A, Rusnak M, Brazinova A, Haagsma J (2017) Years of life lost due to traumatic brain injury in Europe: a cross-sectional analysis of 16 countries. PLoS Med 14:e1002331. https://doi.org/10.1371/ journal.pmed.1002331

Martínez-Solanas È, Basagaña X (2019) Temporal changes in temperature-related mortality in Spain and effect of the implementation of a heat health prevention plan. Environ Res 169:102-113. https:// doi.org/10.1016/j.envres.2018.11.006

Moghadamnia MT, Ardalan A, Mesdaghinia A, Keshtkar A, Naddafi K, Yekaninejad MS (2017) Ambient temperature and cardiovascular mortality: a systematic review and meta-analysis. PeerJ 5:e3574. https://doi.org/10.7717/peerj.3574

Moghadamnia MT, Ardalan A, Mesdaghinia A, Naddafi K, Yekaninejad MS (2018) The effects of apparent temperature on cardiovascular mortality using a distributed lag nonlinear model analysis: 2005 to 2014. Asia-Pacific journal of public health 30:361-368. https://doi.org/10.1177/1010539518768036

Odhiambo Sewe M, Bunker A, Ingole V, Egondi T, Oudin Astrom D, Hondula DM, Rocklov J, Schumann B (2018) Estimated effect of temperature on years of life lost: a retrospective time-series study of low-, middle-, and high-income regions. Environ Health Perspect 126:017004. https://doi.org/10.1289/EHP1745

Onozuka D, Hagihara A (2015) Variation in vulnerability to extremetemperature-related mortality in Japan: a 40-year time-series analysis. Environ Res 140:177-184. https://doi.org/10.1016/j. envres.2015.03.031

Son J-Y, Liu JC, Bell ML (2019) Temperature-related mortality: a systematic review and investigation of effect modifiers. Environmental Research Letters 14:073004. https://doi.org/10.1088/ $1748-9326 / \mathrm{ab} 1 \mathrm{cdb}$

Team RC (2020) R: A language and environment for statistical computing. R foundation for statistical computing, Vienna, Austria Available: https://www.R-project.org/

Watts N, Adger WN, Ayeb-Karlsson S, Bai Y, Byass P, CampbellLendrum D, Colbourn T, Cox P, Davies M, Depledge M et al (2017) The Lancet Countdown: tracking progress on health and climate change. Lancet 389:1151-1164. https://doi.org/10.1016/ S0140-6736(16)32124-9

Xu H, Brook RD, Wang T, Song X, Feng B, Yi T, Liu S, Wu R, Chen J, Zhang Y et al (2019) Short-term effects of ambient air pollution and outdoor temperature on biomarkers of myocardial damage, inflammation and oxidative stress in healthy adults. Environ Epidemiol 3:e078. https://doi.org/10.1097/EE9.0000000000000078

Yang L, Li L, Lewington S, Guo Y, Sherliker P, Bian Z, Collins R, Peto R, Liu Y, Yang R et al (2015) Outdoor temperature, blood pressure, and cardiovascular disease mortality among 23000 individuals with diagnosed cardiovascular diseases from China. Eur Heart J 36:1178-1185. https://doi.org/10.1093/eurheartj/ehv023

Yang J, Yin P, Sun J, Wang B, Zhou M, Li M, Tong S, Meng B, Guo Y, Liu Q (2019) Heatwave and mortality in 31 major Chinese cities: Definition, vulnerability and implications. Sci Total Environ 649:695-702. https://doi.org/10.1016/j.scitotenv.2018.08.332

Yang J, Zhou M, Ren Z, Li M, Wang B, Liu DL, Ou C-Q, Yin P, Sun J, Tong S et al (2021) Projecting heat-related excess mortality under climate change scenarios in China. Nature Communications 12:1039. https://doi.org/10.1038/s41467-021-21305-1

Publisher's note Springer Nature remains neutral with regard to jurisdictional claims in published maps and institutional affiliations. 